\title{
Effect of Intake Vortex Occurrence on the Performance of an Axial Hydraulic Turbine in Sihwa-Lake Tidal Power Plant, Korea
}

\author{
Jin-Hyuk Kim ${ }^{1}$, Man-Woong Heo ${ }^{1}$, Kyung-Hun Cha ${ }^{1}$, Kwang-Yong Kim ${ }^{1}$, \\ Se-Wyan Tac ${ }^{2}$, Yong Cho ${ }^{3}$, Jae-Chun Hwang ${ }^{4}$ and Maria Collins ${ }^{5}$ \\ ${ }^{1}$ Department of Mechanical Engineering, Inha University \\ 253 Yonghyun-Dong, Incheon, 402-751, Republic of Korea, kykim@inha.ac.kr \\ ${ }^{2}$ Department of Tidal Power Plant Construction, Korea Water Resource Corporation \\ Daebu-Dong, Ansan-City, Gyeonggi-do, 425-330, Republic of Korea \\ ${ }^{3} \mathrm{~K}$-water Institute, Korea Water Resource Corporation \\ 462-1 Jeonmin-Dong, Yuseong-Gu, Daejeon 305-730, Republic of Korea \\ ${ }^{4}$ Sihwa-Lake Tidal Power Plant Construction, Daewoo E\&C \\ Daebu-Dong, Ansan-City, Gyeonggi-do, 425-330, Republic of Korea \\ ${ }^{5}$ Hydraulic Laboratory, ANDRITZ Hydro GmbH \\ Lunzerstrasse 78, 4031 Linz, Austria
}

\begin{abstract}
A numerical study to investigate the effect of intake vortex occurrence on the performance of an axial hydraulic turbine for generating tidal power energy in Sihwa-lake tidal power plant, Korea, is performed. Numerical analysis of the flow through an axial hydraulic turbine is carried out by solving three-dimensional Reynolds-averaged NavierStokes equations with the shear stress transport turbulence model. In the real turbine operation, the vortex flows are occurred in both the side corners around the intake of an axial hydraulic turbine due to the interaction between the inflow angle of water and intake structure. To analyze these vortex phenomena and to evaluate their impacts on the turbine performance, the internal flow fields of the axial hydraulic turbines with the different inflow angles are compared with their performances. As the results of numerical analysis, the vortex flows do not directly affect the turbine performance.
\end{abstract}

Keywords: Sihwa-lake tidal power plant, axial hydraulic turbine, vortex flow behavior, numerical analysis, Reynoldsaveraged Navier-Stokes equations.

\section{Introduction}

In relation to the recent issue on renewable energies, tidal power is advantageous compared to other renewable energies such as solar and wind energies, etc. The western coast of Korea is well known as one of the most appropriate places in the world for generating tidal power energy. Due to these advantages, Sihwa-lake tidal power plant that is the world's largest tidal power plant was recently constructed in the middle section of the existing Sihwa-lake dike located near the southern Incheon Port at the western coast of Korea.

With worldwide attention, various technical studies related to the construction of Sihwa-lake tidal power plant have been presented by many researchers in the last decade [1-4]. Bae et al. [5] reported on the detailed design progress and construction technology during the construction of Sihwa-lake tidal power plant. Lee et al. [6] suggested two lake modification alternatives to provide the high quality of water incoming the intake of Sihwa-lake prior to the construction of Sihwa-lake tidal power plant. Cho et al. [7] investigated the field measurements, numerical modeling, and estimations of potential tidal power energy in Sihwa-lake bay prior to the construction of a tidal power plant. Lee et al. [8] proposed the reciprocal power effectiveness through a numerical study on the application of the ocean current power generators combined with Sihwa-lake tidal power plant. Lastly, the current completed construction and operation status of Sihwa-lake tidal power plant were introduced by Tac et al. [9].

On the other hand, experimental and computational studies on a hydraulic turbine for generating effective energy in a tidal power plant have been carried out widely so far. Lipej [10] optimized the design of the runner blade to maximize the

Received August 6 2012; revised August 29, September 2 2012; accepted for publication October 5 2012: Review conducted by Dr. Shogo Nakamura (Paper number O12021J) 
hydrodynamic performance of an axial hydraulic turbine by using a multi-objective evolutionary algorithm. Lee at al. [11] experimentally investigated the relationship between the sluice caisson shape of a tidal power plant and the water discharge capability. Peng et al. [12] used the multi-objective constrained optimization method to minimize the total hydraulic loss and the cavitation coefficient of a runner blade in an axial hydraulic turbine.

As aforementioned, there have been many studies with respect to the construction and development of a tidal power plant. Also, nowadays many studies are diversely being performed for operation status of tidal power plant and further development. This work reports on a numerical study using three-dimensional Reynolds-averaged Navier-Stokes (RANS) equations to investigate the effect of intake vortex occurrence on the performance of an axial hydraulic turbine for generating tidal power energy in Sihwa-lake tidal power plant, Korea. The main goals of this work are to analyze the vortex flow behaviors occurred in both the side corners around the intake of an axial hydraulic turbine and to evaluate their impacts on the turbine performance.

\section{Numerical Analysis}

Sihwa-lake tidal power plant consists of ten axial hydraulic turbines for generating tidal power energy, and eight sluice gates for discharging sea water. In this work, the computational domain includes a single axial hydraulic turbine in the numerical analysis, as shown in Fig. 1. This turbine model, which consists of three runner blades and sixteen wicket gates, operates at a speed of $64.29 \mathrm{rpm}$, with a head condition of $5.82 \mathrm{~m}$.

The flow field in the computational domain was analyzed by solving three-dimensional steady-state incompressible RANS equations with a finite volume solver, the commercial code ANSYS CFX 11.0 [13]. The runner blade and wicket gate profile creations and computational mesh generations were performed through ANSYS Blade-Gen and Turbo-Grid, respectively, whereas ANSYS Design-Modeler and ICEM-CFD were applied to design the sea, generator, draft tube liner, and lake, and to generate their computational meshes, respectively. ANSYS CFX-Pre, CFX-Solver, and CFX-Post were applied for defining boundary conditions, solving, and post-processing, respectively.

The k- $\omega$-based shear stress transport (SST) model [14] was used as a turbulence closure model for accurate prediction of flow separation under adverse pressure gradient [15]. This model uses k- $\omega$ and k- $\varepsilon$ models, respectively, in the near-wall region and the bulk domain, and a blending function ensures smooth transitions between these two models. Accuracy of the numerical scheme in prediction of turbulent flows depends strongly on treatment of wall shear stress. In this work, to benefit from the SST model, high

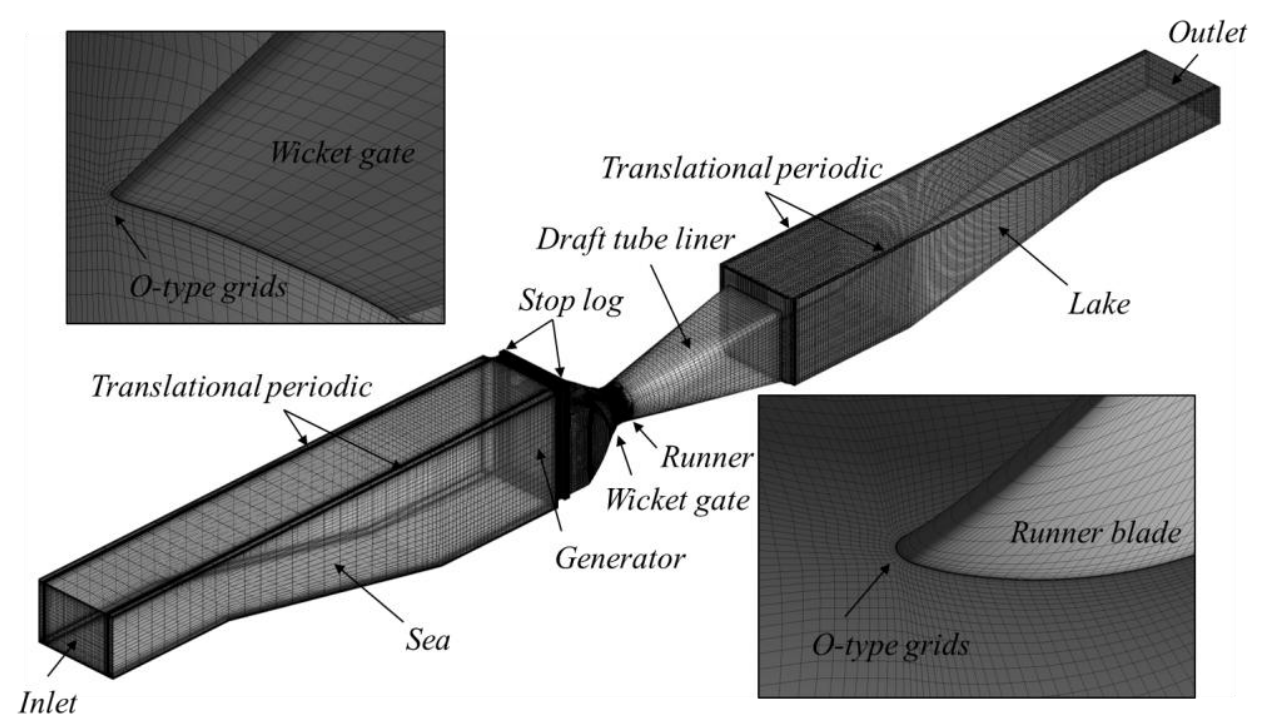

Fig. 1 Computational domain and grids

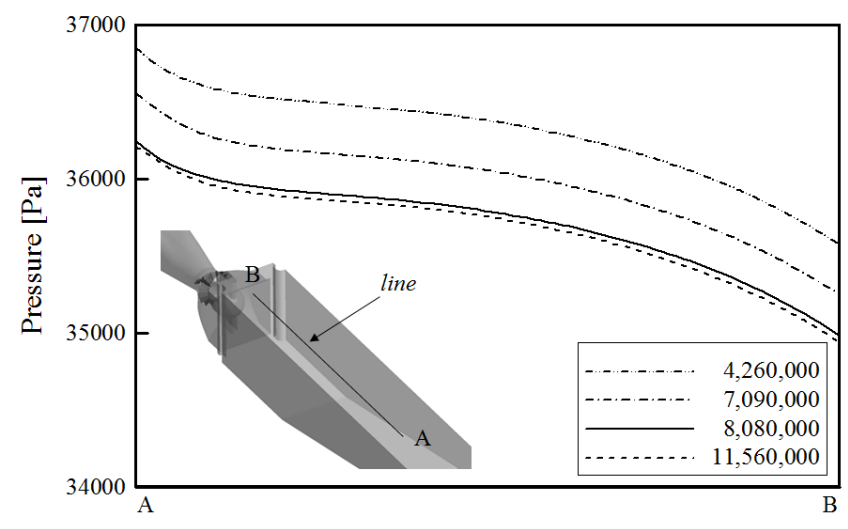

Fig. 2 Result of grid dependency test 
resolution of the boundary layer was assured with more than 10 mesh points, and the near-wall grid resolution was adjusted to keep $y+\leq 2$ to accurately capture wall shear stress and also to implement low-Reynolds-number SST model [13].

As shown in Fig. 1, the computational domain for numerical analysis consists of six domains which are sea, generator, wicket gate, runner, draft tube liner, and lake domains. A structured grid system was constructed in the computational domain with O-type grids near the runner blade and wicket gate surfaces and H-type grids in other regions, as shown in Fig. 1. The grid-dependency test was conducted with various numbers of grids, and the results are shown in Fig. 2 for the static pressure distributions near the surface of sea. The static pressure values along the line A to B calculated with approximately 8,000,000 and 11,500,000 grid points have almost the same values as shown in Fig. 2. Hence, approximately 8,000,000 grid points were used to define the whole computational domain for further numerical analyses.

Water was used as the working fluid. The velocity of $1.2 \mathrm{~m} / \mathrm{s}$ with the inflow angle of $30^{\circ}$ (the real inflow direction) and an area-averaged static pressure were set at the inlet and outlet of the computational domain, respectively. The upper boundaries of sea and lake were considered as free-slip surfaces, while the solid boundaries in the computational domain were considered as adiabatic, no-slip, and hydraulically smooth walls. The translational periodic conditions were set at the sea and lake side interface. Frozen-Rotor method was applied as the connection method between the rotating runner and stationary domains.

Root-mean-square (RMS) values of the equation residuals for convergence criteria were set to be at least $10^{-4}$ for all equations. The physical time scale was set to be $1 / \omega$, where $\omega$ is the angular velocity of the runner blade. The computations have been performed by an Intel Core I7 CPU having clock speed of $2.94 \mathrm{GHz}$. Here, each calculation was subdivided into eight task, and the data transfer was performed by using the MPICH2 [16]. The converged solutions were obtained after 1,000 iterations and the computational time was about approximately $24 \mathrm{hrs}$.

\section{Results and Discussion}

\subsection{Validation of Numerical Results}

In the real turbine operation with the inflow angle of $30^{\circ}$, the vortex flows occurred in both the side corners around the intake of an axial hydraulic turbine, as shown in Fig. 3(a). It is thought that this is probably due to the interaction between the inflow angle of water and intake structure. These vortex flow behaviors appear to have an adverse effect on the entire system performance of the axial hydraulic turbine. To analyze and investigate these vortex flow phenomena, three-dimensional RANS analyses were carried out, and their results were validated in comparison with the real vortex flow behaviors. Figure 3 shows the vortex flows predicted by the RANS analysis and the real vortex flow phenomena occurred in both the side corners around the intake of the axial hydraulic turbine. As shown in Fig. 3(b), the trajectories and locations of the vortex flows predicted by the
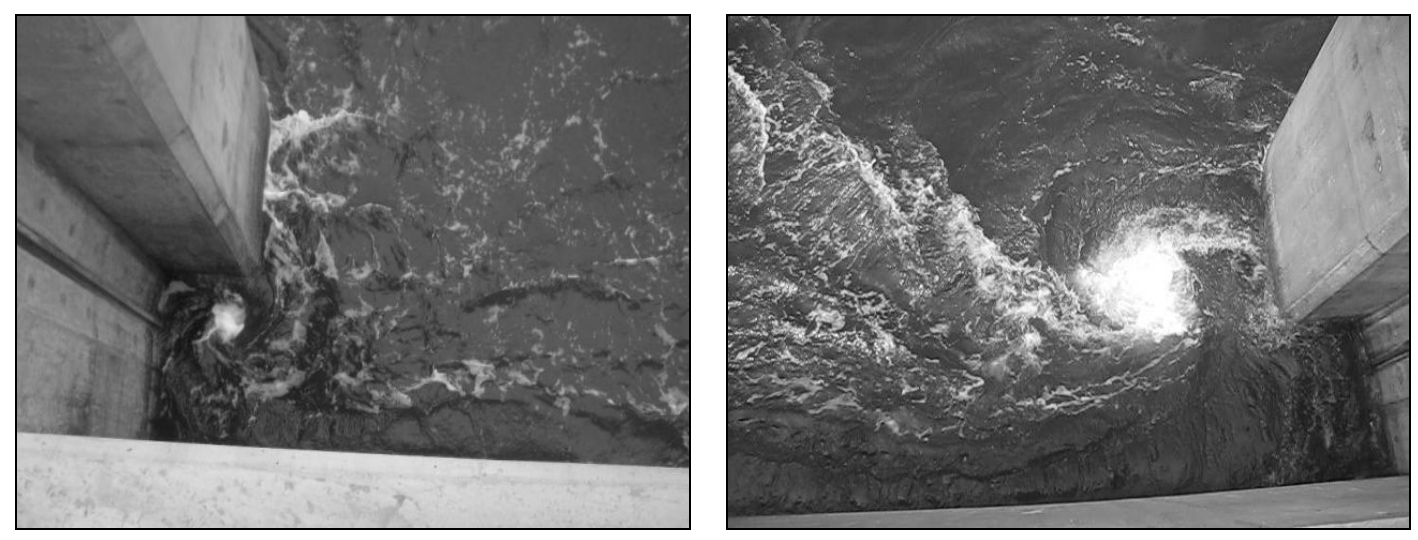

(a) Real vortex phenomena around the intake of turbine
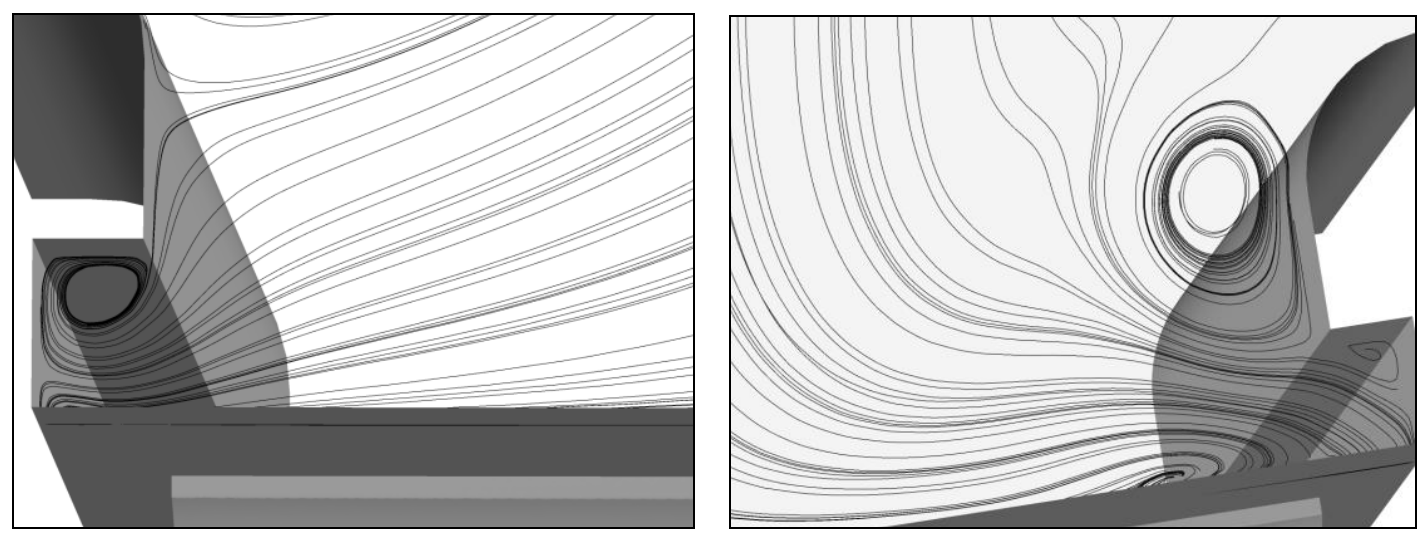

(b) Numerical vortex phenomena around the intake of turbine

Fig. 3 Validation of the numerical results 
RANS analysis are qualitatively in good agreements with the real vortex flow behaviors. Thus, the numerical analysis of this work can be considered to have reliable accuracy considering the results of these validations.

\subsection{Analyses of the internal flow fields and performances of turbines with the inflow angles}

To analyze the vortex flow phenomena and to evaluate their impacts on the turbine performance, the internal flow fields of the axial hydraulic turbines with the different inflow angles were compared with their performances. Figure 4 shows the velocity vectors near the sea level around the intake of turbines with the different inflow angles. In Figs. 4(a) (c), the velocity vectors are smoothly driven along the passage. However, the extensive vortex flow behaviors caused by the large inflow angles are occurred in the side corners around the intake of turbine in Figs. 4(d) (f). Fig. 4(d) indicates the vortex flow behaviors in real inflow condition (the inflow angle of $30^{\circ}$ ) also shown in Fig. 3. In the meantime, these extensive vortex flow behaviors tend to increase as the inflow angle increases from $30^{\circ}$ to $50^{\circ}$.

Figure 5 shows the isosurfaces having a vortex swirling strength of $9.5 \times 10^{-7}$ for the turbines with the inflow angles of $0^{\circ}, 30^{\circ}$, and $50^{\circ}$. In Fig. 5(a), small vortices are built out in the gate slots of stop log on both side corners due to a recirculation caused by the geometry. In contrast, the extensive vortex flow behaviors induced by the large inflow angles of $30^{\circ}$ and $50^{\circ}$ are formed in the side corner as shown in Figs. 5(b) and (c). However, the trajectories of these extensive vortices became extinct certainly before reaching the runner blade of the turbine.

Figure 6 shows the static pressure distributions in streamwise direction at the 20 and $80 \%$ spans on the suction and pressure sides of the runner blade for the turbines with the inflow angles of $0^{\circ}, 30^{\circ}$, and $50^{\circ}$. As shown in Fig. 6 , the static pressures on the

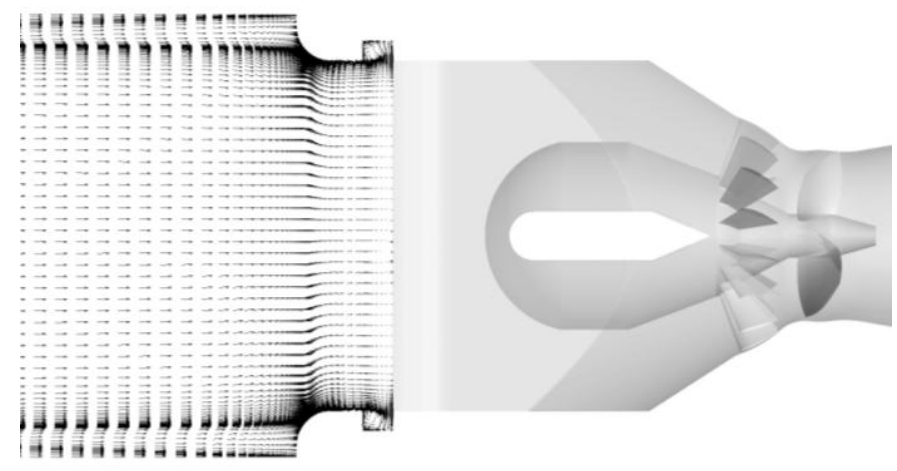

(a) Inflow angle of $0^{\circ}$

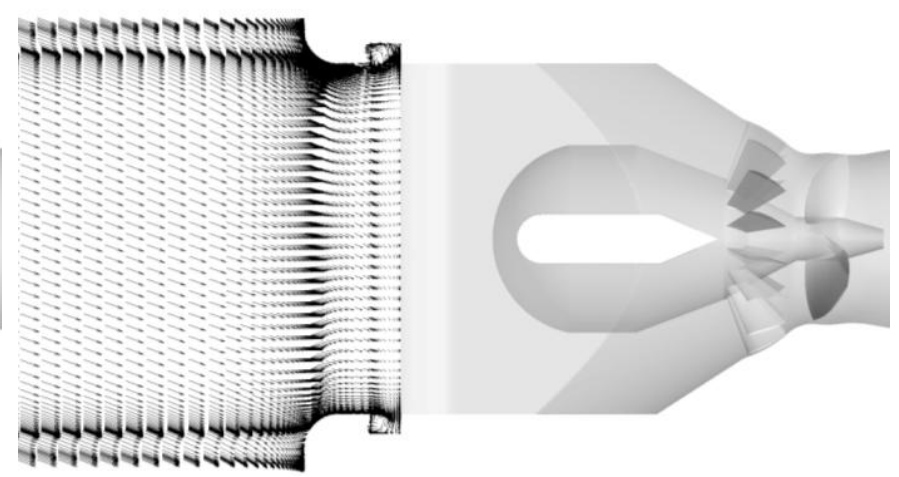

(b) Inflow angle of $10^{\circ}$

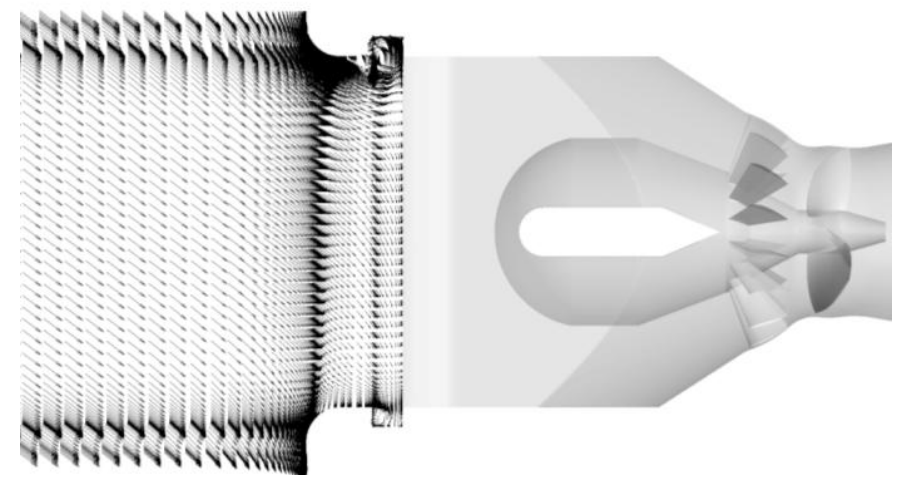

(c) Inflow angle of $20^{\circ}$

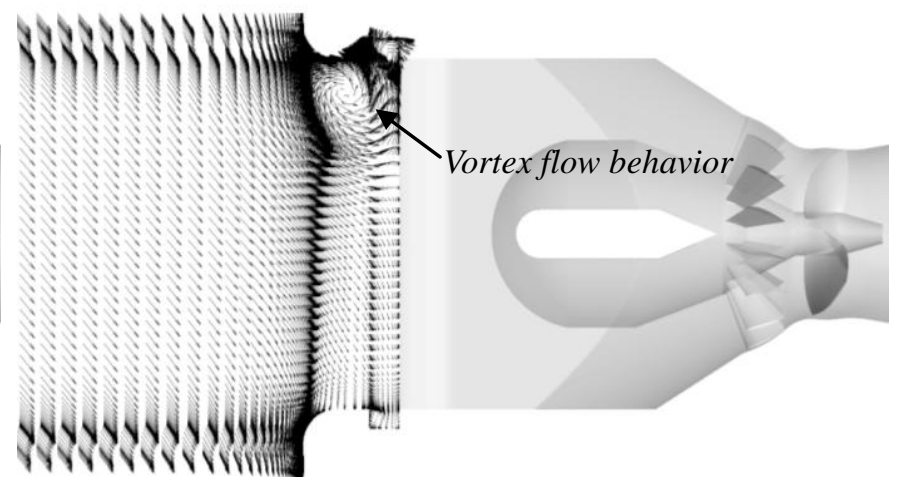

(d) Inflow angle of $30^{\circ}$

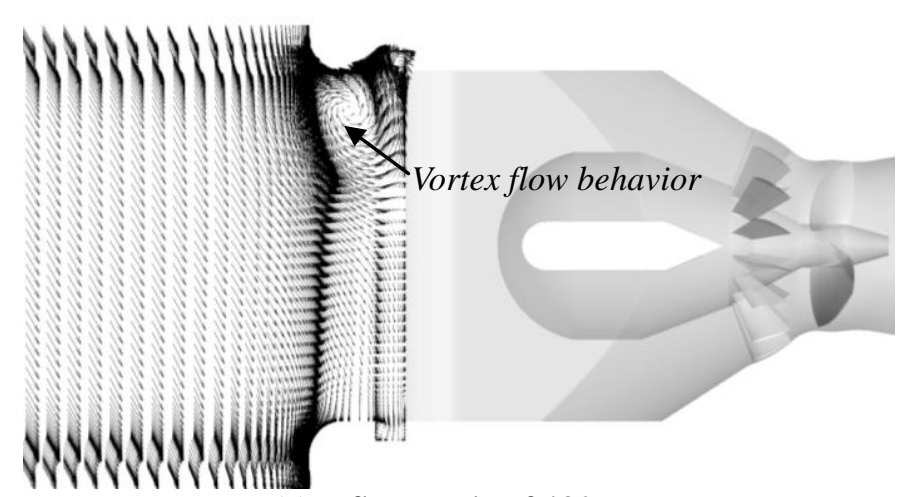

(e) Inflow angle of $40^{\circ}$

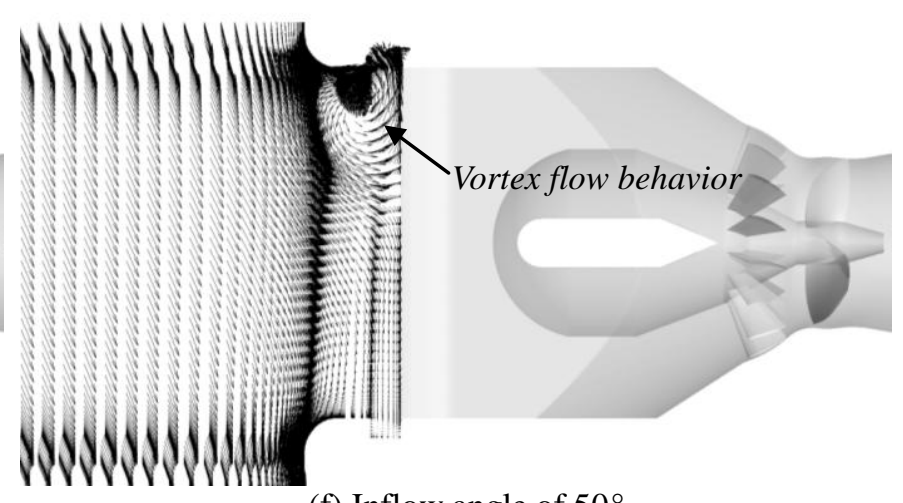

(f) Inflow angle of $50^{\circ}$

Fig. 4 Velocity vectors near the sea level around the intake of turbine 


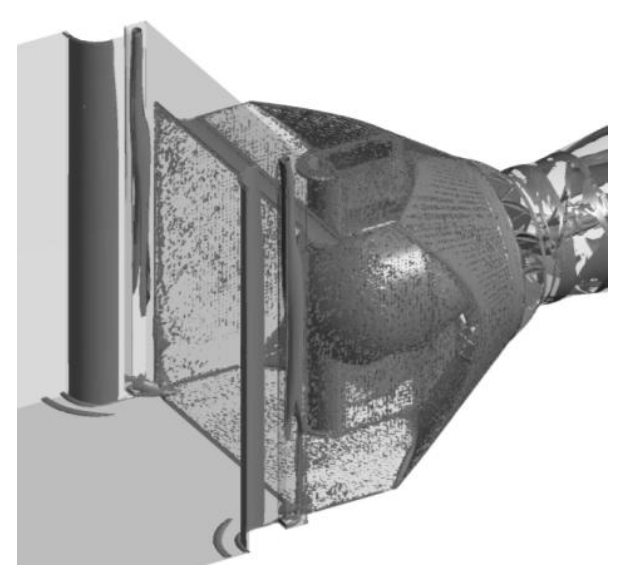

(a) Inflow angle of $0^{\circ}$

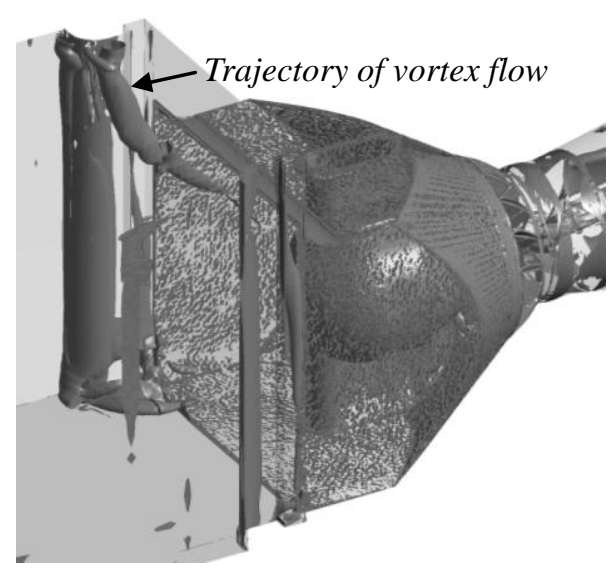

(b) Inflow angle of $30^{\circ}$

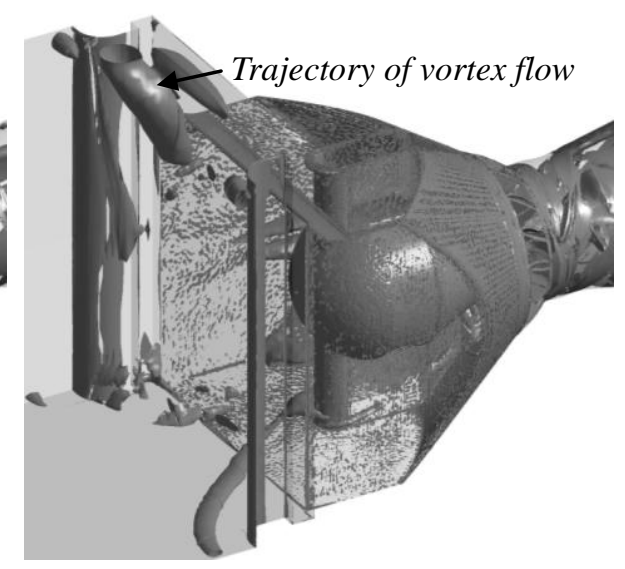

(c) Inflow angle of $50^{\circ}$

Fig. 5 Isosurfaces with a vortex swirling strength of $9.5 \times 10^{-7}$

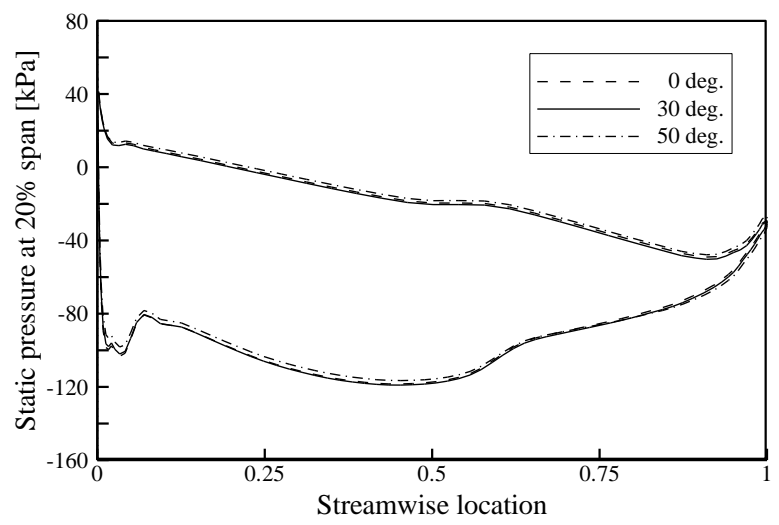

(a) At $20 \%$ span

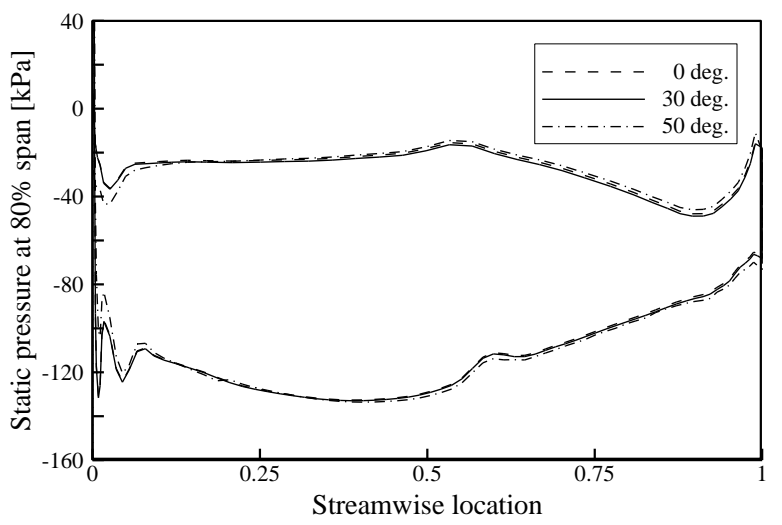

(b) At $80 \%$ span

Fig. 6 Static pressure distributions on runner blade surfaces

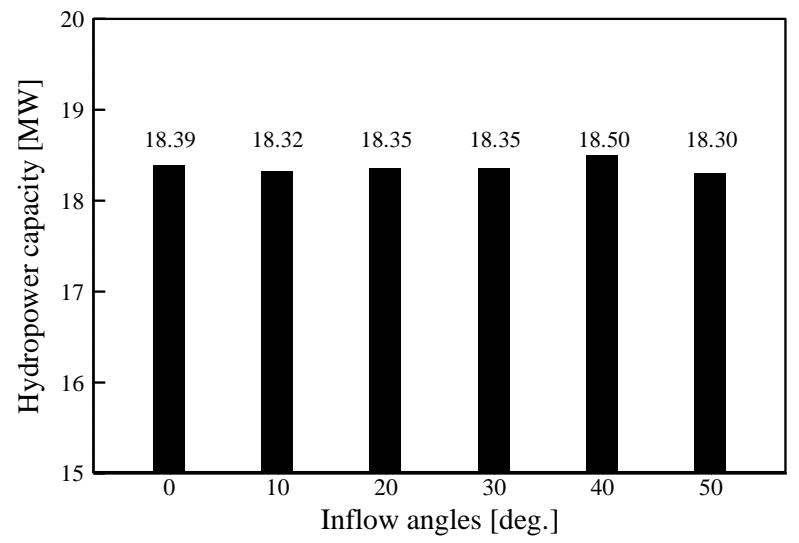

Fig. 7 Hydropower capacities for the turbines with the different inflow angles

suction and pressure sides for all turbines with the different inflow angles show generally similar values at most of the spanwise locations. These results indicate that the intake vortex occurrence due to large inflow angle does not affect the turbine performance.

The hydropower capacities for the turbines with the different inflow angles are compared in Fig. 7. As shown in Fig. 7, it can be seen that the hydropower capacity of the turbine is not affected by the inflow angle, and the value is approximately 18.3 MW. Consequently, these results show that the extensive vortex flow behaviors occurred in the side corners around the intake of turbine do not directly affect on the turbine performance. 


\section{Conclusion}

A numerical study based on three-dimensional RANS equations has been carried out to investigate the effect of intake vortex occurrence on the performance of an axial hydraulic turbine for generating tidal power energy in Sihwa-lake tidal power plant, Korea. In the real turbine operation, the vortex flow behaviors were occurred in both the side corners around the intake of an axial hydraulic turbine due to the interaction between the inflow angle of water and intake structure. To analyze these vortex phenomena and to evaluate their impacts on the turbine performance, the internal flow fields of the turbines with the different inflow angles were calculated. From the results of numerical analysis, it was found that the trajectories of the extensive vortex flows occurred in the intake of the turbine become extinct certainly before reaching the runner blade of the turbine. Eventually, it was found that these extensive vortex flow behaviors do not directly affect the turbine performance.

\section{Acknowledgments}

This work was supported by the National Research Foundation of Korea (NRF) grant funded by the Korea government (MEST) (No. 2012-0005159).

RANS

RMS

\section{Nomenclature}

\author{
SST Shear stress transport \\ $\omega \quad$ Angular velocity of the runner blade [rad/s]
}

\section{References}

[1] Kim, K. H. and Song, K. B., 2007, “Calculation of Generation Power Integrating Sihwa Tidal into Power Systems,” Journal of Korean Institute of Illuminating and Installation Engineers, Vol. 21, No. 1, pp. 157-163.

[2] Son, J. W., Kim, J. K., Choi, D. H. and Kim, K. Y., 2009, "The Special Features of Main Facilities for Sihwa T.P.P," Proceedings of the KFMA Annual Meeting 2009 (in Korea), pp. 449-454.

[3] Cho, Y. B., Wee, J. H. and Kim, J. I., 2010, "Status and Feasibility Study on Tidal Energy Technology," Journal of Energy Engineering (in Korea), Vol. 19, No. 2, pp. 103-115.

[4] Kim, G. W., Lee, M. E., Lee, K. S., Park, J. S., Jeong, W. M., Kang, S. K., Soh, J. G. and Kim, H. N., 2012, “An Overview of Ocean Renewable Energy Resources in Korea," Renewable and Sustainable Energy Reviews, Vol. 16, No. 4, pp. $2278-2288$.

[5] Bae, Y. H., Kim, K. O. and Choi, B. H., 2010, “Lake Sihwa Tidal Power Plant Project,” Ocean Engineering, Vol. 37, No. 5-6, pp. 454-463.

[6] Lee, S. I., Kim, B. C. and Oh, H. J., 2002, "Evaluation of Lake Modification Alternatives for Lake Sihwa, Korea," Environmental Management, Vol. 29, No. 1, pp. 57-66.

[7] Cho, Y. S., Lee, J. W. and Jeong, W., 2012, “The Construction of a Tidal Power Plant at Sihwa Lake, Korea,” Energy Sources, Part A: Recovery, Utilization and Environmental Effects, Vol. 34, No. 14, pp. 1280-1287.

[8] Lee, S. H., Lee, S. H., Jang, K. S., Lee, J. E. and Hur, N. K., 2008, "A Numerical Study on the Application of the Ocean Current Power Parks with a Tidal Power Plant," Proceedings of the KFMA Annual Meeting 2008 (in Korea), pp. 547-552.

[9] Tac S. W., Jeon S. M. and Han K. S., 2011, "Current Construction of the World's Largest Sihwa-Lake Tidal Power Plant," Proceedings of the KFMA Annual Meeting 2011 (in Korea), pp. 183-196.

[10] Lipej, A., 2004, "Optimization Method for the Design of Axial Hydraulic Turbines," Proceedings of the Institution of Mechanical Engineers, Part A: Journal of Power and Energy, Vol. 218, No. 1, pp. 43-50.

[11] Lee, D. S., Oh, S. H., Yi, J. H., Park, W. S., Cho, H. S., Kim, D. G., Eom, H. M. and Ahn, S. J., 2010, "Experimental Investigation on the Relationship between Sluice Caisson Shape of Tidal Power Plant and the Water Discharge Capability," Renewable Energy, Vol. 35, No. 10, pp. 2243-2256.

[12] Peng, G., Cao, S., Ishizuka, M. and Hayama, S., 2002, "Design Optimization of Axial Flow Hydraulic Turbine Runner: Part II - Multi-Objective Constrained Optimization Method," International Journal for Numerical Methods in Fluids, Vol. 39, No. 6, pp. 533-548.

[13] ANSYS CFX-11.0, 2006, ANSYS CFX-Solver Theory Guide, ANSYS Inc.

[14] Menter, F. R., 1994, "Two-Equation Eddy-Viscosity Turbulence Models for Engineering Application,” AIAA Journal, Vol. 32, No. 8, pp. 1598-1605.

[15] Bardina, J. E., Huang, P. G. and Coakley, T. J., 1997, “Turbulence Modeling Validation," 28th AIAA Fluid Dynamics Conference, Snowmass Village, USA, AIAA-1997-2121.

[16] Thakur, R., Gropp, W. and Toonen, B., 2005, "Optimizing the Synchronization Operations in Message Passing Interface OneSided Communication,” International Journal of High Performance Computing Applications, Vol. 19, No. 2, pp. 119-128. 